\title{
Urban Public Green Space Equity against the Context of High-Speed Urbanization in Wuhan, Central China
}

\author{
Hongzan Jiao ${ }^{1,2, *}$, Chengcong $\mathrm{Li}^{3}$, Yang $\mathrm{Yu}^{1, * \mathbb{C}}$ and Zhenghong Peng ${ }^{3}$ \\ 1 Department of Urban Planning, School of Urban Design, Wuhan University, Wuhan 430072, China \\ 2 Engineering Research Center of Human Settlements and Environment of Hubei Province, \\ Wuhan 430072, China \\ 3 Department of Graphics and Digital Technology, School of Urban Design, Wuhan University, Wuhan 430072, \\ China; leechc@whu.edu.cn (C.L.); pengzhenghong@whu.edu.cn (Z.P.) \\ * Correspondence: jiaohongzan@whu.edu.cn (H.J.); yuyang1@whu.edu.cn (Y.Y.); Tel.: +86-27-6877-3062 (H.J.)
}

Received: 20 September 2020; Accepted: 4 November 2020; Published: 11 November 2020

check for updates

\begin{abstract}
This study examines the relationship between equity of public green space and urban expansion/sprawl under high-speed urbanization. Equity of urban public green space indicates the degree to which urban public green spaces are distributed spatially in an equal way, with regard to the spatial variation of residents' "need" for green space. In emerging economies such as China, especially in developing or underdeveloped cities such as Wuhan, central China, rapid urban growth challenges the capacity of the state to provide infrastructure and services for its urbanites equally. In order to research the relationship between industrial development and green space equity under the background of rapid urbanization, the use of quantitative methods to more accurately measure the degree of spatial inequality is essential. In this study, the accessibility of urban public green space in Wuhan is examined based on the two-step floating catchment area method (2SFCA) method at multilevel radius; the urban public green space accessibility of Wuhan in 2013 and 2016 are acquired, and the link between changes in accessibility of urban public green spaces and urban expansion in Wuhan is discussed. It is found that industrial development takes precedence over green space. With its vigorous development, industrial land attracts increasing population, resulting in the drastic decline of the service capacity of green spaces, which is not conducive to the long-term development of the city.
\end{abstract}

Keywords: urban public green space; accessibility index; urban sprawl

\section{Background}

Over the past few decades, China witnessed unprecedented urbanization, driven by multiple forces such as globalization, centralization, industrialization, and marketization. Between 1978 and 2013, the percentage of China's urbanization soared from $17.9 \%$ to $53.7 \%$. Such rapid rate of urbanization gave rise not only to dramatic urban expansion, but also various challenges such as resource depletion, food insecurity, and land degradation [1,2]. Besides these negative impacts, China's rapid economic development and transition brought about escalated social contradictions in recent years. In particular, inequality across regions has caused increasing concerns among both decision-makers and the general public, because it indicates the unequal distribution of opportunities among regions, which may pose a threat to social stability or even national unity [3,4]. Making the issue more important, the Chinese people's awareness of the inequity has grown in recent years, in areas such as medical care, education, and other aspects of welfare, including urban public green space.

Urban public green space is one of the important elements of urban planning, and it is an integral component of a city's green infrastructure, playing an important part in urban ecological 
environment [5]. Urban green space is a site for planting trees, flowers, and plants, and arranging supporting facilities. Urban public green space offers widely recognized economic [6] and ecological benefits [7], including improving air quality [8], reducing urban heat [9], providing recreational opportunities and promoting people's physical and mental well-being $[10,11]$. Because of its many benefits, equity in the planning and distribution of urban park green space has been the subject many researchers [12,13].

Commonly used indicators for equity of green space include per capita park area and green coverage. However, these indicators do not directly reflect the spatial pattern and distribution of green spaces, or the actual use of these spaces by residents [8]. To this end, researchers have proposed indicators such as accessibility and service area ratio to evaluate the equity of urban public green space distribution. Among them, accessibility is an important tool in assessing the equity of urban public green space distribution. The term accessibility refers to the ease of moving from any point in space to a certain destination, reflecting the resistance people meet in the process of reaching a destination, usually measured by indicators such as distance, time, and cost. Accessibility is commonly applied in empirical studies to assess spatial equity and to reveal spatial inequality in the distribution of essential services and opportunities, and the results can be used to support decision-making $[13,14]$.

In the context of the rapid urbanization of megacities such as Wuhan, the central urban area often faces shortage in land resources due to population agglomeration, thus squeezing spaces for public service facilities, especially urban public green space; in suburban areas, the original natural ecological spaces are often gradually encroached as the city spreads. Despite the fact that urban government does plan for urban public green spaces, they tend to lag behind the development of other land uses. Especially when industrial land use is prioritized, large areas of land in suburban locations may be converted to industrial uses. Therefore, the contradiction between rapid urban expansion and the equity of the distribution of urban public green space has become our concern.

However, few studies can be found on this subject. Therefore, the present study aims to discuss the mechanism and problems in the equity of urban public green space amid rapid urbanization by describing the changes in the accessibility of urban public green space over time along with the rapid expansion of the city.

Using multisource data of the case city, the present study describes its urban expansion/sprawl process, changes in its population, land use distribution, distribution of urban public green spaces; then, using accessibility evaluation methods, change in the equity of urban public green space is discussed and the reasons for these changes caused by urban expansion are analyzed.

The remainder of this study is structured as follows: Section 2 introduces the research area and data processing; Section 3 presents the research method and results analysis; Section 4 presents the conclusion and possible application in planning practices.

\section{Research Area and Data Processing}

\subsection{Research Area}

Wuhan is the capital city of Hubei Province and is the city with the largest population in central China. The city is located at the intersection of the middle reach of the Yangtze River (the third longest river in the world) and its largest branch, the Han River. Wuhan Municipality comprises 13 administrative districts, including seven central urban districts and six suburban districts. In March 2016, "Yangtze River economic belt development plan" incorporated Wuhan City as a megacity; in December, the National Development and Reform Commission explicitly requested Wuhan to speed its development as a national central city supported by four functions: national economic center, high-level scientific and technological innovation center, commercial trade and logistics center, and an international communication center. Since the year 2001, the government has promulgated a series of policies regarding green spaces: large-scale parks in the city are open and free of charge to the public since 2001; in 2002, investment was increased to build waterfront parks in Hankou, Wuchang, 
and Hanyang; the "Green Space Planning of Wuhan Central Urban Area (2000-2020)" proposes access to green space of residents within $500 \mathrm{~m}$ to their homes, a per capita green space area in the central urban area (within the inner city ring) of $8.03 \mathrm{~m}^{2} /$ person, and a per capita green space area in the main urban area of $16.8 \mathrm{~m}^{2} /$ person. In 2005, Wuhan became the 53rd national-level garden city. The "Green Space Planning of Wuhan Central Urban Area (2011-2020)" proposes access to green space for residents within $500 \mathrm{~m}$ to their homes, access to parks within $800 \mathrm{~m}$, and view of lakes or rivers within $1000 \mathrm{~m}$, by 2020. The addition of large areas of parks, green squares, and greenways greatly improved the green coverage, thus the overall environment and image of the city. The goals of the urban green space system plan have been constantly clarified and improved, and detailed and differentiated plans have been developed for each urban district.

The research area of this study is the urban development zone as delineated in the Wuhan City Master Plan (2010-2020), approved by the State Council (Figure 1).

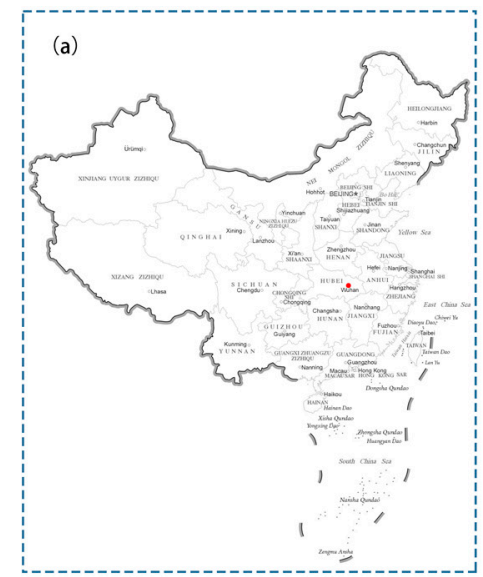

(b)
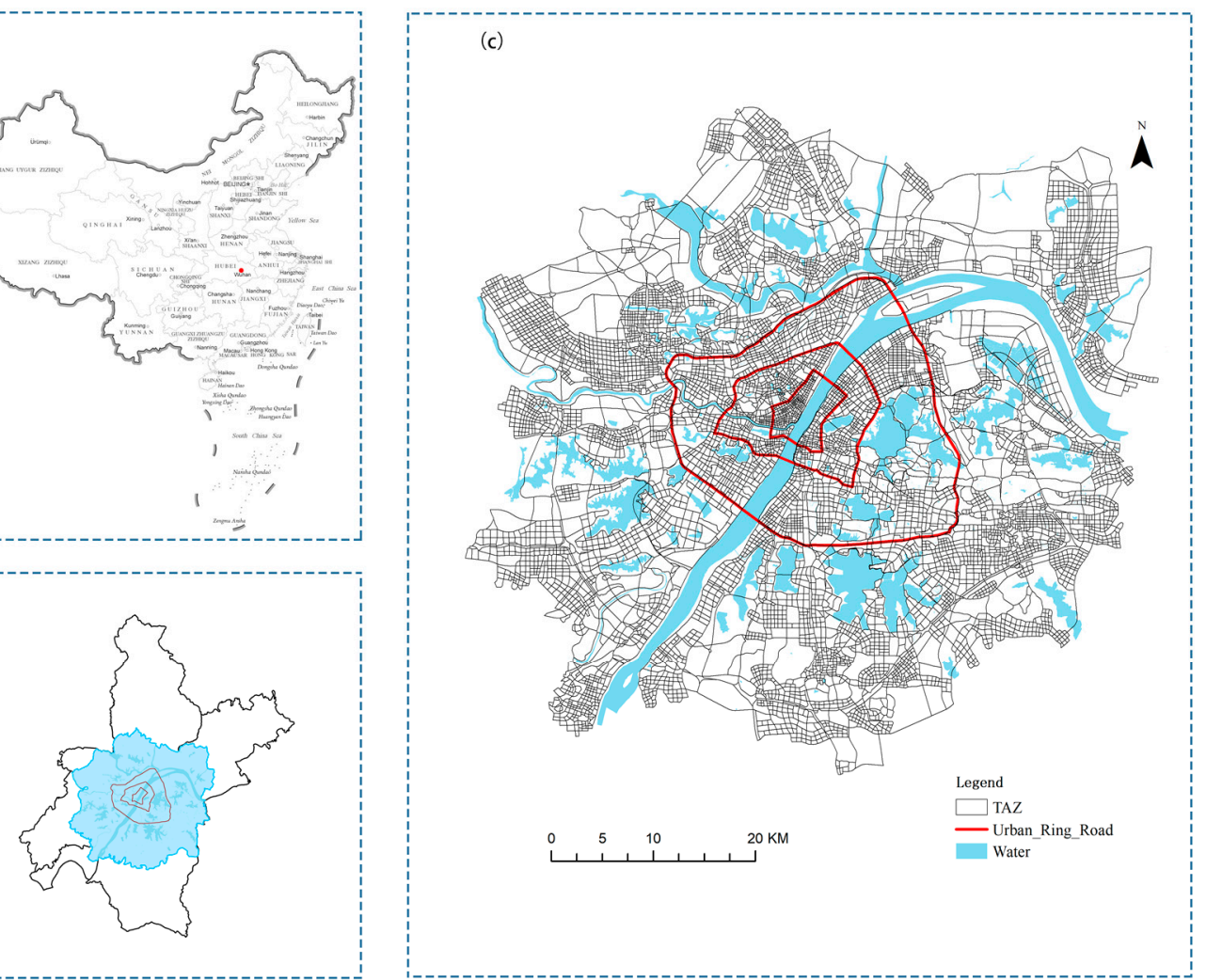

Figure 1. Wuhan's location in China (a); the location of the study area in Wuhan (b); study area and traffic analysis zone (TAZ) distribution (c).

\subsection{Research Scale and Data Source}

In this study, traffic analysis zone (TAZ) [15] is used as the basic research unit which refers to zones divided in different sizes and shapes by the road network. In this study, the traffic condition in a TAZ is regarded as basically homogenous and thus can be regarded as a whole.

Data used in this study include: (1) Google Earth historic image of Wuhan City in 2013 and 2016; (2) vector data of urban green space of Wuhan in 2016; (3) population of subdistricts from the Wuhan Public Security Bureau for the years 2013 and 2016; (4) OpenStreetMap (OSM) road network data of Wuhan in the research year 2016; (5) building base and building height data for 2016 obtained from the Wuhan Planning and Research Institute; (6) current land use data from the Master Plan of Wuhan City 2016; and (7) socioeconomic data from the Wuhan Statistical Yearbook for the study years. Data were collected in the year 2016; the 2013 information was acquired from the changes in remote sensing data from 2013 and 2016. 


\subsection{Data Processing}

Data processing comprised three major steps, regarding urban public green space, identification of urban expansion area, and population data processing, as illustrated in Figure 2.

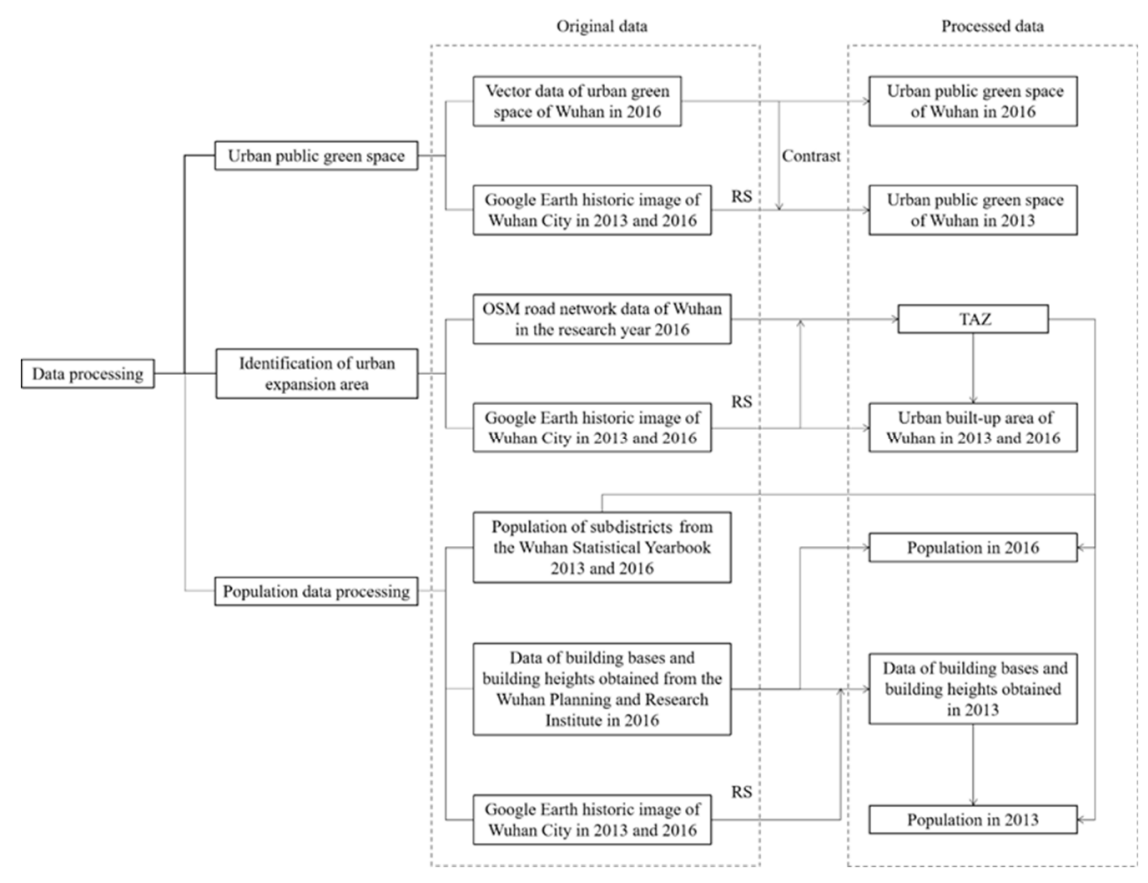

Figure 2. Diagram of data-processing procedures.

\subsubsection{Urban Public Green Space}

Definition of urban public green space in this study is based on the five categories stipulated in the "urban green space classification standards" (CJJ/T 85-2002) by the Ministry of Construction in 2002, namely, comprehensive park, community park, specialized park, belt park, and roadside park. Among them, comprehensive park, community park, and roadside park are classified based on the scale, facility, target group, and service area of the park; specialized parks are classified based on their theme or features; while the belt parks are classified by their forms. Using vector data of urban green space of Wuhan in 2016, and comparing Google Earth historic images of Wuhan City in 2013 and 2016, the distribution map of green spaces of Wuhan City in 2013 was acquired, as illustrated in Figure 3.

\subsubsection{Identification of Urban Expansion Area}

Since the mid-20th century, developed western countries witnessed accelerated suburbanization. Urban built-up area spread out, resulting in excessive expansion of urban space and disordered sprawl. Scholars called this phenomenon "urban sprawl" [16,17]. Urban sprawl not only erodes open spaces such as farmland and forests around the city, but also negatively affects urban spatial structure, residential structure, urban transportation, ecological environment and visual quality [18]. Urban sprawl became a hot topic which caught attention in western academic disciplines such as urban planning, urban economics and environmental protection $[19,20]$. Researchers hence put forward concepts such as smart growth, compact city, and new urbanism, aiming to guide the healthy and orderly development of cities.

With the acceleration of economic globalization, many developing countries are also facing challenges brought by urban sprawl $[21,22]$. China is currently amidst rapid urbanization and the growth rate of its built-up area is faster than that of its population growth. As the trend of urban sprawl is still going strong in China, it is necessary to analyze and solve the problem of urban sprawl. 


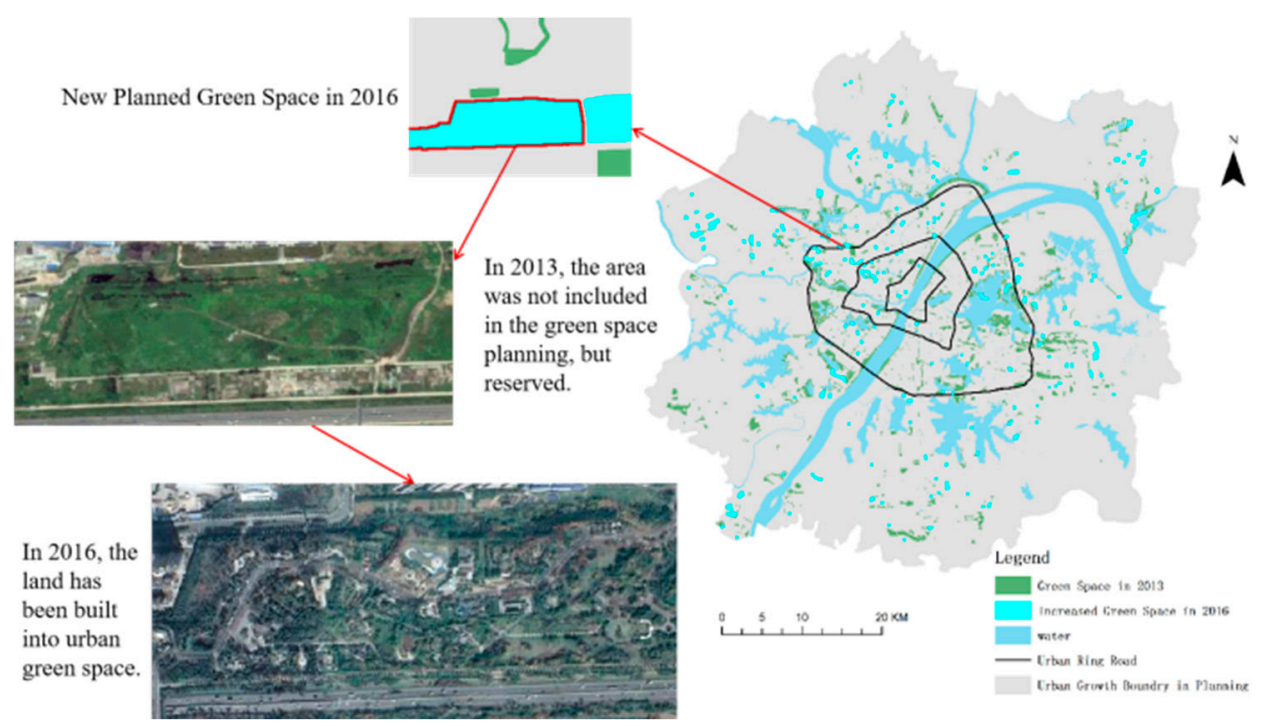

Figure 3. The urban public green space of Wuhan in 2013 and 2016.

To this end, one fundamental issue is to identify areas of urban expansion. In previous research, many scholars use the boundaries of urban built-up areas extracted from remote sensing from different time periods to identify and urban expansion. This study also uses this method to identify areas of urban expansion.

Currently, there is no uniform definition of the concept of built-up area, as demonstrated by the different understanding of built-up area by various scholars [23,24]. In general, built-up area refers to the area in the administrative area of a city, where buildings, public facilities, and roads are relatively concentrated. The built-up area described in this study is delineated by boundary information of urban built-up areas extracted from remote sensing imagery. The periphery of built-up area is usually rural, which is shown in remote sensing images as large areas of farmland or forest land, while the inside of the built-up area is usually aggregated buildings and public facilities.

Urban built-up area is identified with the built-up and bareness index (BBI) by using the reflectance from the NIR band to the SWIR1 band in the TM/ETM+ data. The normalized difference built-up index (NDBI) can usually be used to extract the urban built-up area; however, considering the developing area of urban space, the bare land areas will also be regarded as the urban built-up area. Thus, the built-up and bareness index is defined as follows:

$$
\begin{gathered}
\mathrm{NDBI}_{O L I 2-O L I 3}=\frac{R_{O L I 2}-R_{O L I 3}}{R_{O L I 2}+R_{O L I 3}} \\
\mathrm{NDBI}_{O L I 4-O L I 3}=\frac{R_{\text {OLI4 }}-R_{\text {OLI3 }}}{R_{O L I 4}+R_{\text {OLI3 }}} \\
B B I_{O L I}=\mathrm{NDBI}_{\text {OLI2-OLI3 }}+\mathrm{NDBI}_{\text {OLI4-OLI3 }}
\end{gathered}
$$

where $R_{O L I 2}, R_{O L I 3}$, and $R_{O L I 4}$ are the reflectance of the OLI data in band 2, 3, and 4, respectively.

The traffic analysis zones (TAZs) in the study area are delineated based on the open-source OSM road network data and the built-up areas and bare land area extracted from the BBI OLI $_{\text {image in each }}$ TAZ, and the proportion is calculated. The boundaries of built-up area of Wuhan in 2013 and 2016 are present in the Figure 4. 


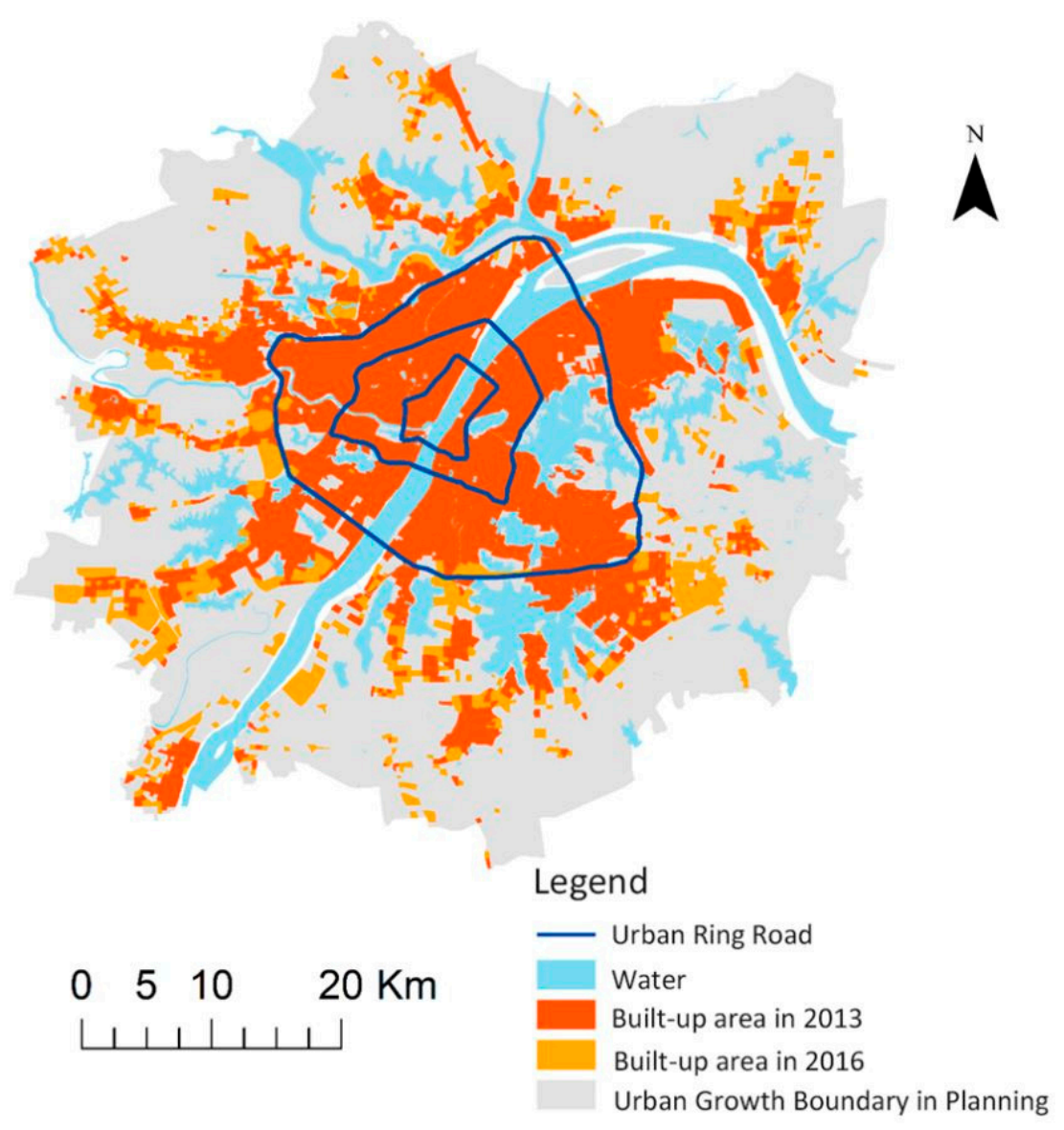

Figure 4. Urban built-up area of Wuhan in 2013 and 2016.

\subsubsection{Population Data Processing}

Using the building data of Wuhan in 2016, data of building bases and building heights obtained from the Wuhan Planning and Research Institute in 2016, and comparing Google Earth historic images of Wuhan City in 2013 and 2016, the data of building bases and building heights of Wuhan City in 2013 were acquired.

Then, using data of building base and building height obtained from the Wuhan Planning and Research Institute in 2016, and that of 2013 as acquired through the method described above, the total floor area of the buildings in each TAZ in 2013 and 2016 were calculated.

Population data were obtained from the Wuhan Public Security Bureau and was allocated to each TAZ according to the floor area of buildings in each subdistrict. The results are shown in Figures 5 and 6. By subtracting the TAZ population data for 2013 from that of 2013, demographic change from 2013 to 2016 was calculated. The results are shown in Figure 7. 


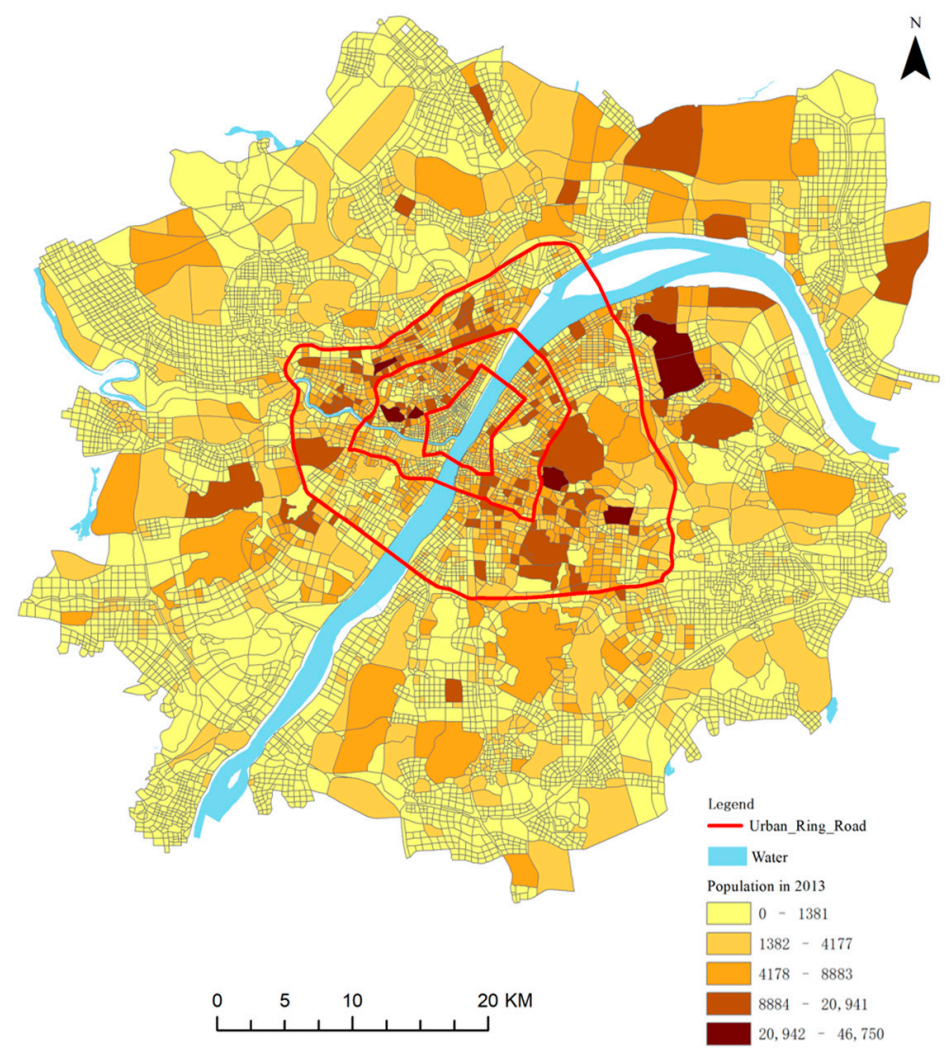

Figure 5. Population in 2013.

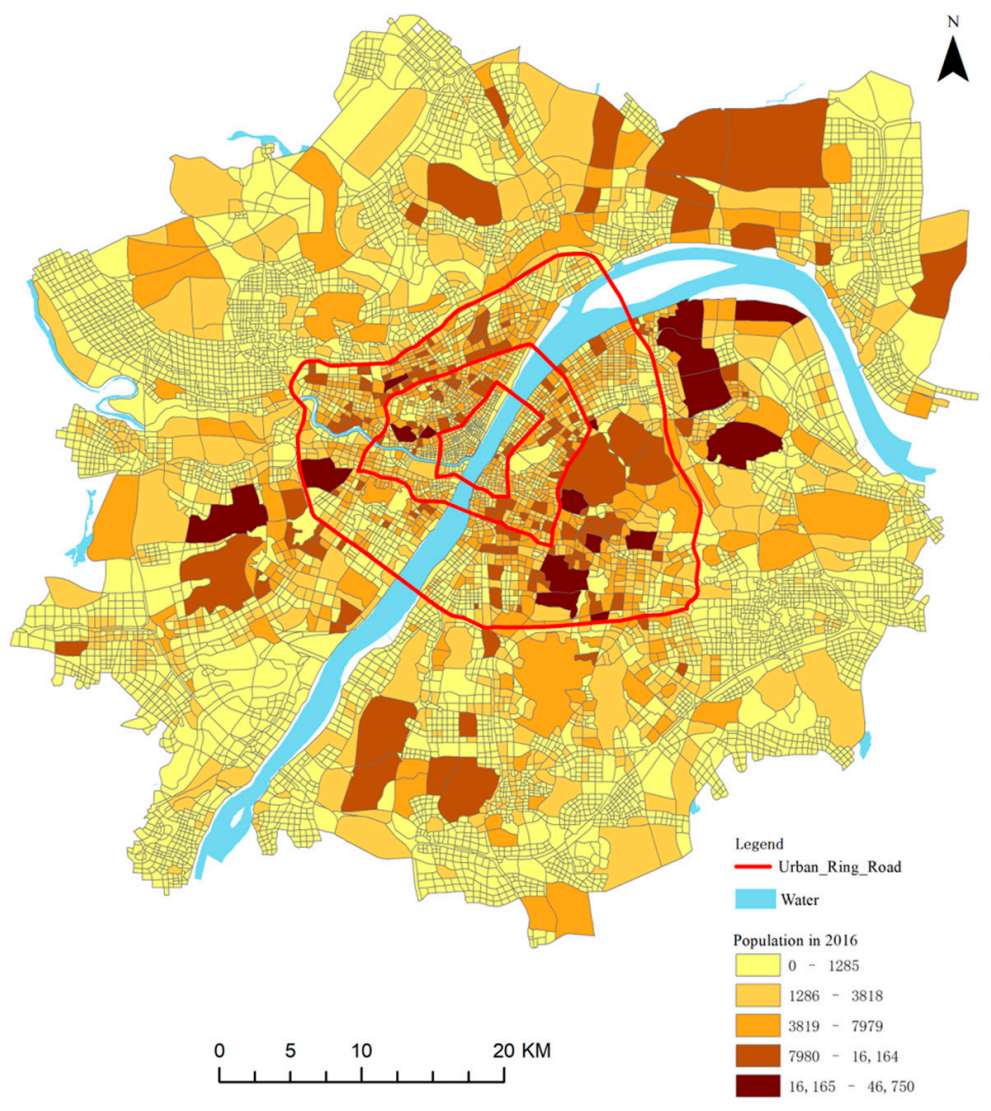

Figure 6. Population in 2016. 


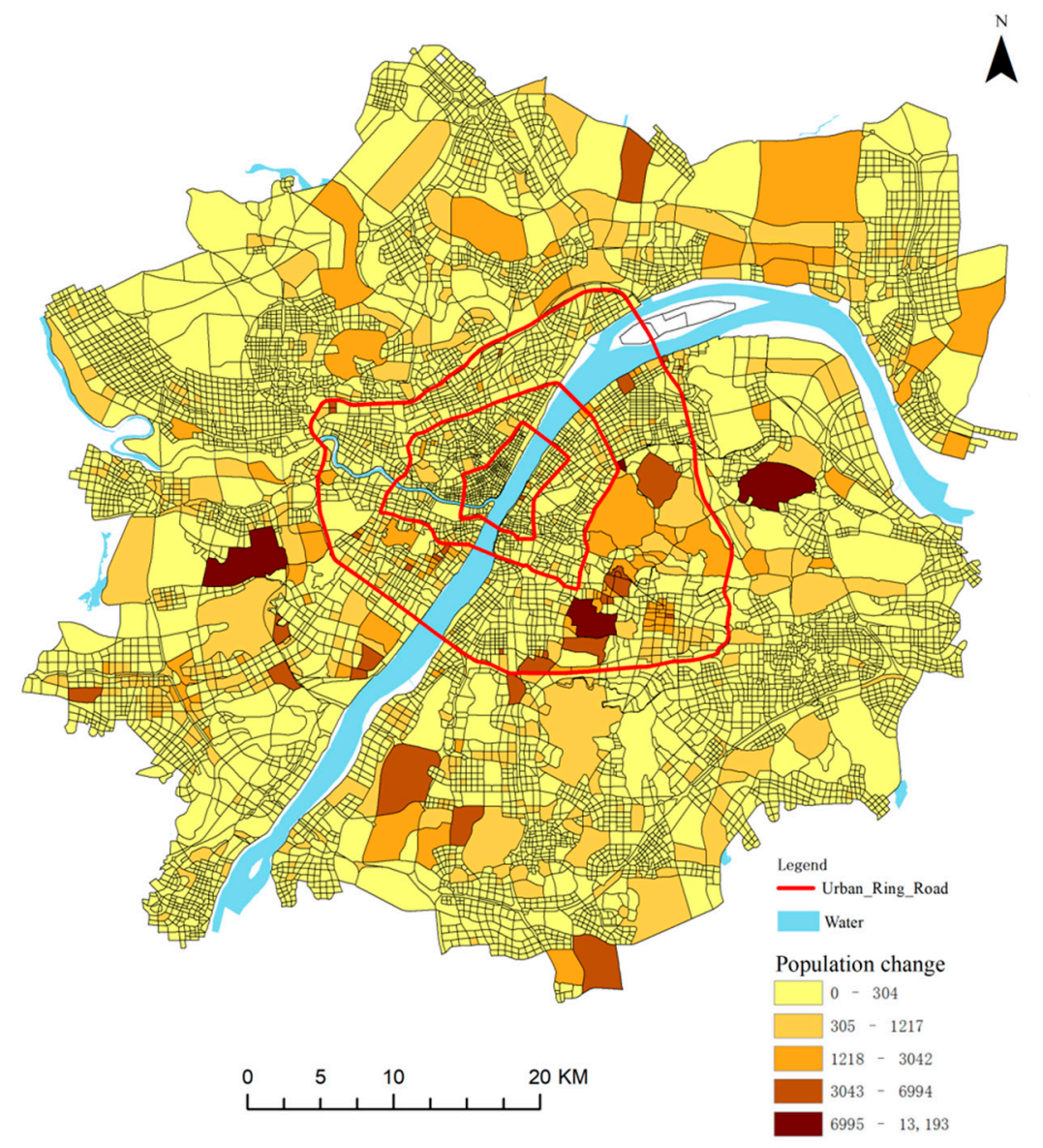

Figure 7. Population change in 2016 over 2013.

\section{Research Methods and Results}

\subsection{Research Methods}

Accessibility is a key concept used in human geography to evaluate the spatial distribution of public facilities. It is also adopted by the Chinese government as an important principle in public facility allocation. Accessibility is affected by many factors. Generally, the term accessibility we commonly use refers to spatial accessibility, which emphasizes the spatial nature of accessibility, ignoring nonspatial factors such as personal preference, race, and class $[25,26]$.

As the evaluation of spatial accessibility can identify areas of scarcity of public services, it has been used as an effective way to measure the equity of the distribution of public service facilities $[13,27,28]$ and has also drawn extensive attention from domestic and international researchers who have developed diverse research methods [29,30]. Among them, the two-step floating catchment area method (2SFCA) has been widely received and applied [31]. In subsequent research, various extensions to the methods emerged, forming a large family of 2SFCA models [32-35].

The basic idea of 2SFCA is shown in Figure 8. In the first search, a public facility $j$ is used as the center point of supply, and the number $k$ of demand points within search radius $d_{0}$ is identified to calculate the supply-demand ratio $R_{j}$. In the second search, each point $i$ is used as the center point of demands, and the number $j$ of demand points within search radius $d_{0}$ is identified to calculate the supply-demand ratio $R_{j}$. All Rj values are then summed to acquire the accessibility $A_{i}^{F}$ of point $i$.

$$
A_{i}^{F}=\sum_{j \in\left\{d_{i, j} \leq d_{0}\right\}} R_{j}=\sum_{j \in\left\{d_{i, j} \leq d_{0}\right\}}\left(\frac{S_{j}}{\sum_{k \in\left\{d_{k, j} \leq d_{0}\right\}} D_{k}}\right)
$$


where $i$ stands for a demand point; $j$ a supply point; $A_{i}^{F}$ represents the accessibility at the demand point $i$ as calculated with the 2SFCA method; $d_{i, j}$ is the distance between the demand point $i$ and supply point $j ; R_{j}$ is ratio of the facility size to the population of supply point $j$ within the search radius $d_{0} ; S_{j}$ represents the supply scale of supply point $j ; D_{k}$ represents the demand scale of demand point $k$.

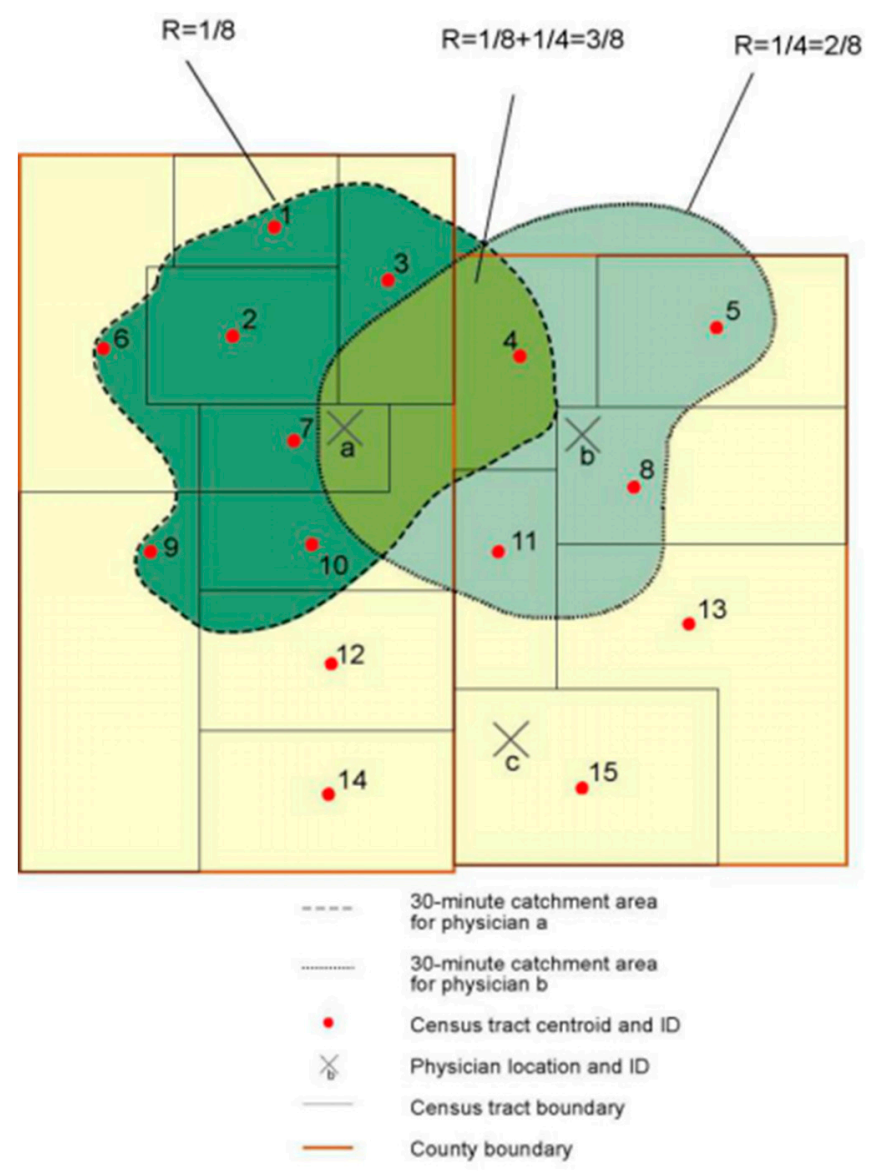

Figure 8. Diagram of the two-step floating catchment area method (2SFCA) [36].

Another commonly used method for evaluating accessibility is the gravity model, also known as the potential model. In fact, the 2SFCA and gravity model methods stem from the same theoretical framework, which consider the scale of both the supply and demand of facilities.

The two models take different approaches to the impact of the distance between supply and demand on accessibility. The gravity model method uses a continuous distance attenuation function, taking into account the decreasing service capability of facilities over distance; however, the method does not set a limit on the effective search radius of a facility. The 2SFCA method takes a dichotomy approach to distance attenuation, i.e., the accessibility is considered the same within the search radius threshold and completely unreachable outside the search radius.

In addition, there are several other commonly used methods for evaluating accessibility: the nearest distance method [37] considers only the distance factor, but not the scale of the supply or demand point; the Huff model [38] considers the facility scale and distance factor, but not the scale of demand; the kernel density method [25] stems from the same framework as the gravity model, which considers only the Euclidean distance, but not the impact of the actual traffic network or the scale of the demand point.

In summary, among the many evaluation methods of spatial accessibility, 2SFCA and the gravity model are the most widely used, and with the most comprehensive factors considered. Although the models share similar theoretical basis, 2SFCA is easier to understand and more operable due to 
its two-step floating catchment approach. Therefore, it has drawn much attention and gained great development.

In this study, the multicatchment sizes 2SFCA, an improved form of 2SFCA, is adopted to calculate the accessibility of urban public green space. Based on the 2SFCA, the multilevel radius 2SFCA sets multilevel search radii in accordance with the scale of the facility from a supply perspective. This extended form is called multicatchment sizes 2SFCA (MC2SFCA).

The multicatchment sizes 2SFCA method analyzes the accessibility of park green space from two aspects: supply (area of green space) and demand (population distribution). At the TAZ scale, the center of mass can replace the population center of gravity, therefore the accessibility to the center of mass can be regarded as the average accessibility of the residents inside the TAZ. On the supply side, the urban public green spaces are classified in terms of different sizes and different service radii. This approach overcomes the weaknesses of traditional green space evaluation methods that ignore the spatial distribution, ecosystem service, and the social equity of resource provision of urban green spaces, and is more reasonable than the 2SFCA approach with a single radius and can more accurately reflect the actual travel of citizens.

Based on the information available in the study, the urban public green spaces are classified based on their sizes and are assigned with different service radii accordingly: municipal park, with an area $10-100 \mathrm{hm}^{2}$, serves the entire city and the adjacent area at a radius of $3000 \mathrm{~m}$; district park, with an area $5-10 \mathrm{hm}^{2}$ and a service radius of $1500 \mathrm{~m}$; residential area park, with an area $2-5 \mathrm{hm}^{2}$ and a service radius of $750 \mathrm{~m}$.

In accordance with the classification of park green spaces and using the corresponding service radius, the calculation method follows.

Using the park green space as the supply point $j$, the total number of demand points $i$ within the service radius $d_{0}$ is searched, and the calculated supply-demand ratio $R_{j}$ represents the service capacity of the park green space:

$$
R_{j}=\frac{S_{j}}{\sum_{k \in\left\{d_{k, j} \leq d_{0}\right\}} D_{k}}
$$

In Equation (5), $R_{j}$ is the service capacity of the park green space, $S_{j}$ is the area size of the park green space, $d_{k, j}$ is the distance between $k$ and $j, d_{0}$ is the upper limit of travel distance, and $D_{k}$ is the total population within the search domain. In this first step, a search field is established using the park green space as the center and the supply-demand ratio of each park green space is calculated to study the usage of the park green space.

In the second step, for each demand point $i$, the park green spaces within the travel distance $d_{0}$ is searched and the total number $j$ is calculated. The sum of all supply-demand ratios in the range is calculated as $A_{i}{ }^{F}$, which represents the accessibility of each demand point $i$ and can also be interpreted as the park green space resources actually available at the demand point.

$$
A_{i}^{F}=\sum_{j \in\left\{d_{i, j} \leq d_{0}\right\}} R_{j}
$$

In Equation (6), $A_{i}^{F}$ is the spatial accessibility of the park green space resources for residents in the TAZ, $R_{j}$ is the area to population ratio of the park green space at location $j$ in the search domain $i$, and $d_{0}$ is the upper limit of travel distance of residents.

This step establishes a search domain with the residential area in the TAZ as the center. Within the upper limit of the travel distance of residents, multiple park green spaces are covered, which provide green space for the residential area. By calculating the sum of the supply-demand ratio of the multiple parks, the spatial accessibility of the TAZ to park green space is obtained. 


\subsection{Results}

The accessibility results calculated using 2SFCA can be interpreted as the per capita park green area that is actually available to the residents. The common method of calculating per capita green space is to divide the total area of urban public green space by the total population in an administrative area or research area. This method ignores the actual distribution of the population, because in reality, residents do not go to urban public green spaces that are too far from their homes, even if they are located in their administrative area. Seemingly similar to the common approach of calculating per capita area of green space by dividing the total area by population, the 2SFCA method takes into account the impact of service radius, which is more in line with the actual situation-urban public green spaces located too far away are often of no service to residents. Therefore, it can be considered that the results of green space accessibility calculated by 2SFCA can be interpreted as the per capita park green area that people can actually use.

\subsubsection{Results of Green Space Accessibility for 2013 and 2016}

Accessibility in the research area is divided into eight levels, as shown in Figures 9 and 10, and the Changes in accessibility in 2016 over 2013 have been shown in Figure 11.

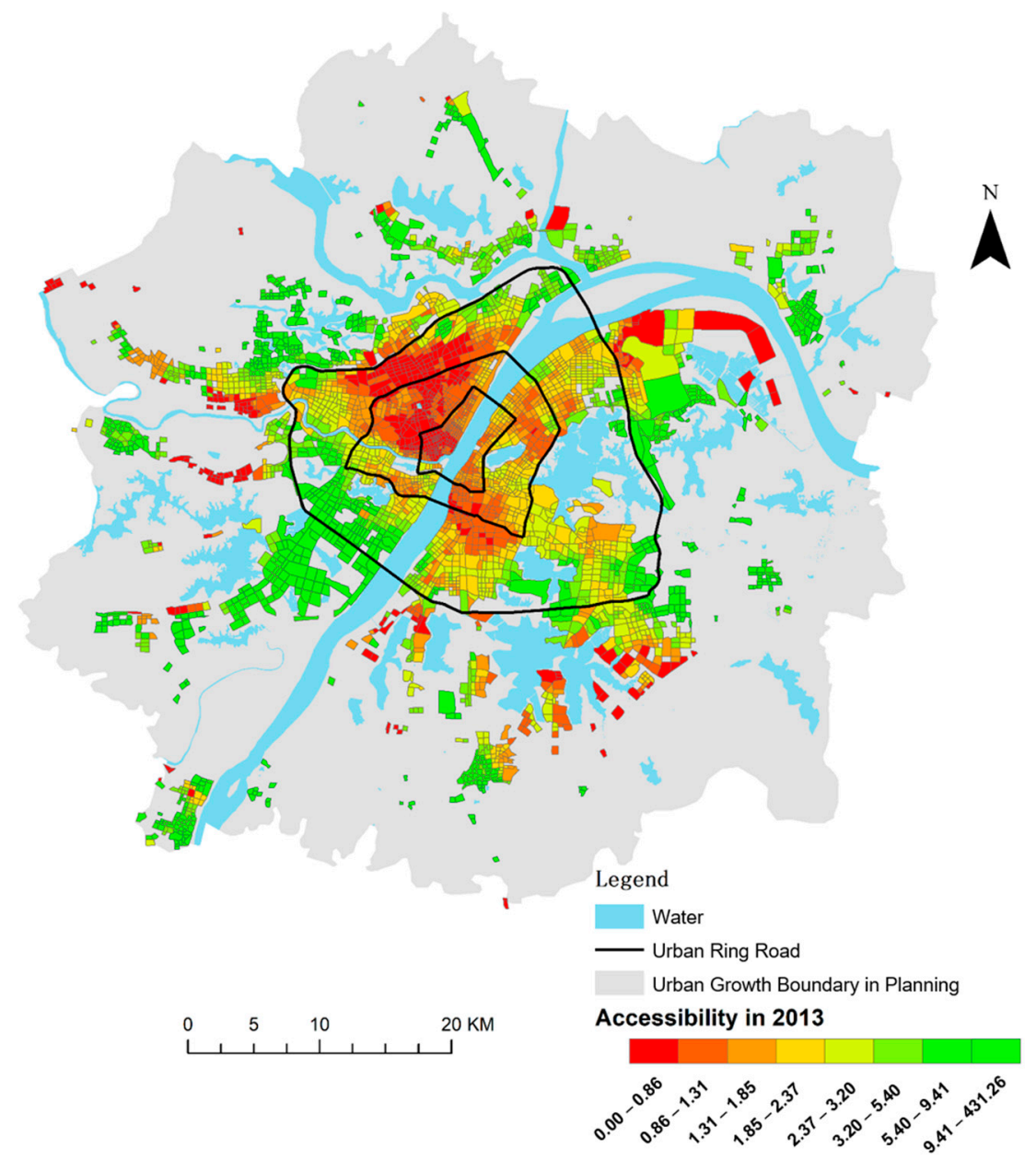

Figure 9. Accessibility in 2013. 


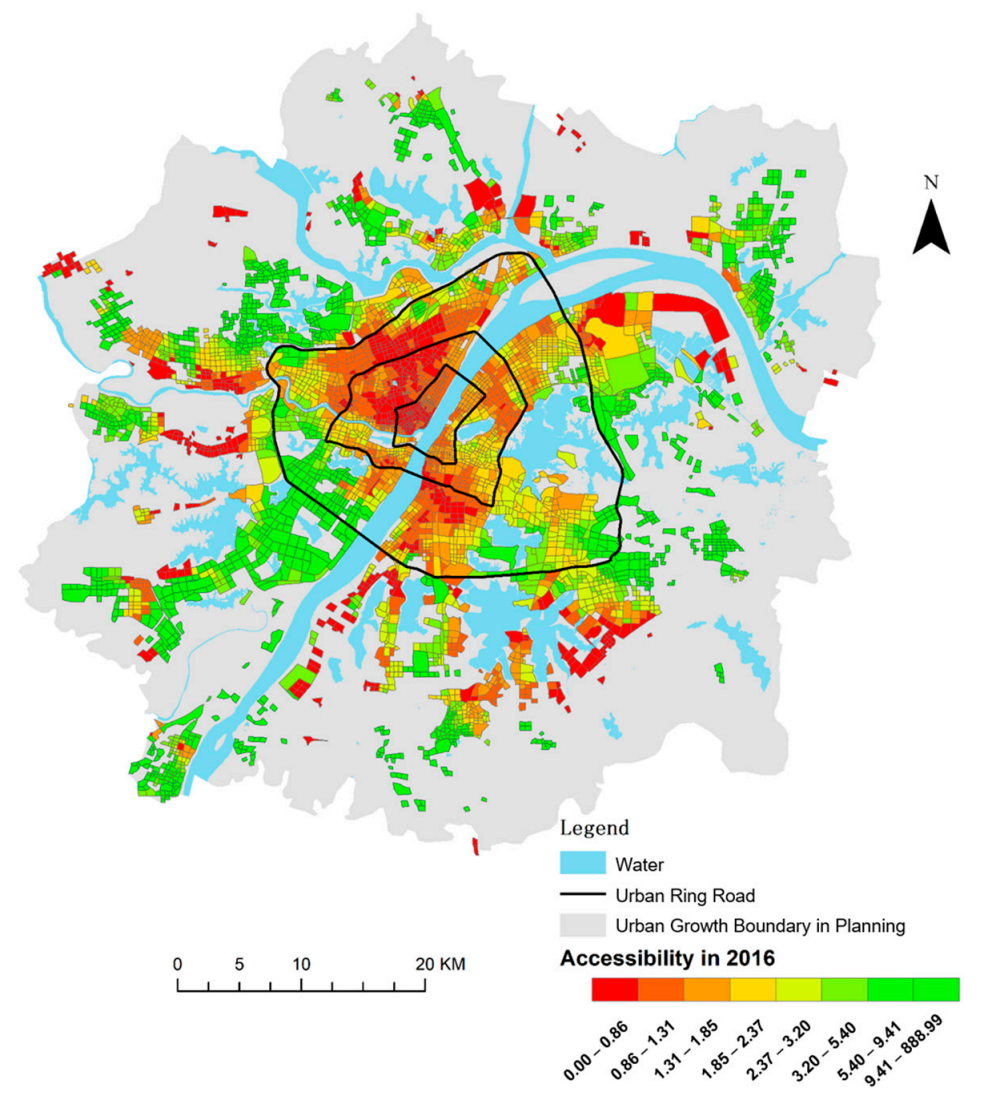

Figure 10. Accessibility in 2016.

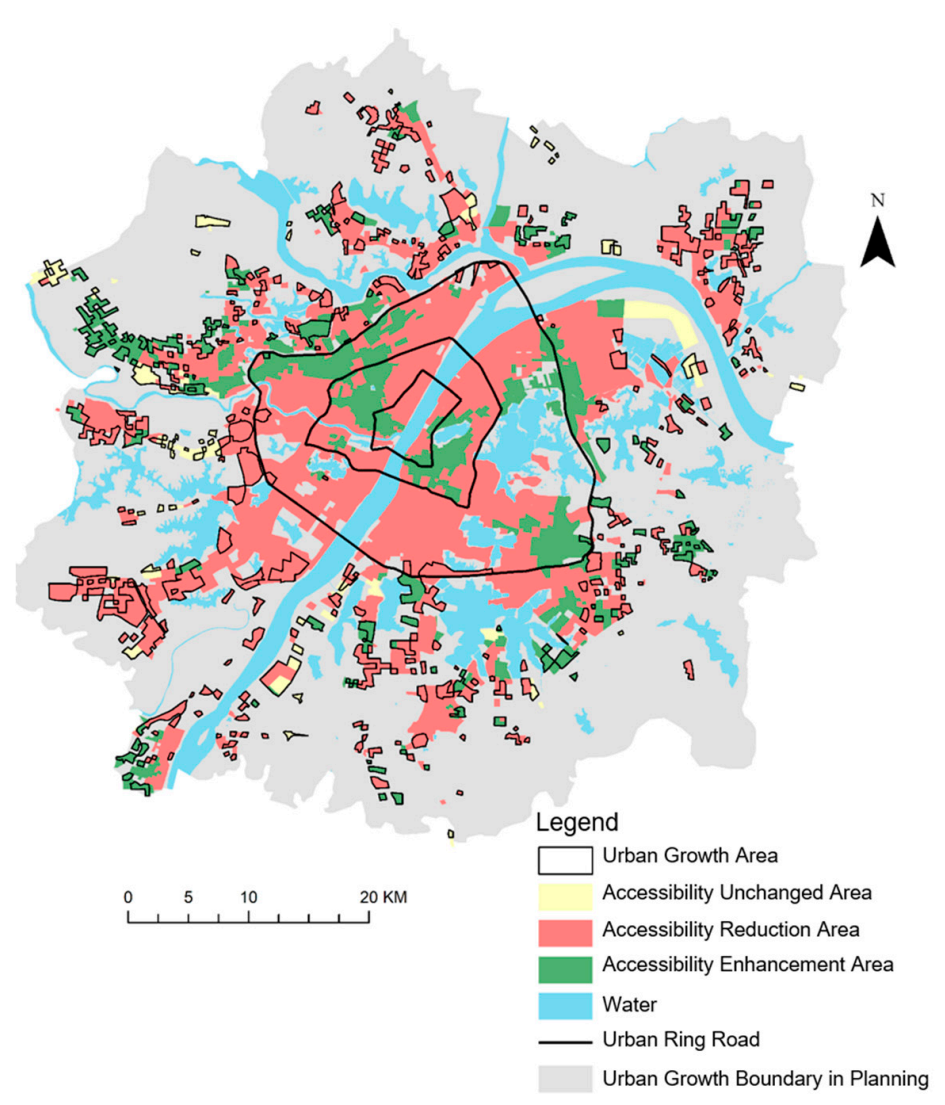

Figure 11. Change in accessibility in 2016 over 2013. 
For the year 2013, accessibility scores of park green spaces within the second ring of the city are low. Since park green space plays the role of disaster prevention and mitigation, this study refers to the "Planning Guideline on Earthquake and Emergency (Outdoor) Refuge in the Central Urban Area of Beijing," taking into account the carrying capacity of park green spaces and residents' comfort, and sets the lower limit of per capita land area at $2 \mathrm{~m}^{2} /$ person. Evidently, part of the areas in the central city could not meet this standard. Then, judged by the more ideal values set in accordance with the "Green Space System Planning for the Central Urban Area of Wuhan (2011-2020)" and through rational distribution of the green space system, the per capita park green space in the central urban area (within the Inner Ring Road) reaches $8.03 \mathrm{~m}^{2} /$ person, the per capita park green area in the main city area reaches $16.8 \mathrm{~m}^{2} /$ person, all areas within the Second Ring Road are unable to meet the standard, and some areas between the Second Ring Road and Third Ring Road cannot meet this standard. As for the main urban area (excluding the Inner Ring Road area and the undeveloped areas with an accessibility of zero), some areas can meet the standards and others cannot.

The reason why all areas within the Inner Ring Road were unable to meet the standard lies in its dense population and the relative scarcity of green spaces. Furthermore, the area between the Second and Third Ring Road is a transitional area where the accessibility in areas between the Third Ring Road to the fringe is generally good, probably due to the small population and abundant and high-quality green spaces, while the zero accessibility areas in the urban fringe need to be better planned and built. The visualized results of the park green space accessibility for the year 2016 are similar to those for 2013. It can be seen that the overall development pattern of park green spaces in Wuhan from 2013 to 2016 is consistent.

\subsubsection{Urban Expansion}

As seen in Figure 4, by interpreting the remote sensing images, the area of urban expansion of Wuhan from 2013 to 2016 is approximately 242.62 square kilometers. The built-up area in 2013 was approximately 736.46 square kilometers and grew by approximately $32.94 \%$ from 2013 to 2016 .

Using the land use data in the 2016 Wuhan City master plan, industrial land use of Wuhan in 2016 is extracted and its spatial distribution presented in Figure 12. The industrial land uses include industrial land types one to three. Comparing the expansion of the built-up area of Wuhan City and the distribution of industrial land areas in 2016, as shown in Figure 13, it is clear that the areas of urban expansion are the concentrated existing or planned industrial areas of Wuhan. Most of the expansion areas are affected by industrial land uses or have expanded outward around the industrial area.

As seen in Table 1, the industrial land accounts for $23.03 \%$ of the total area of urban expansion. Furthermore, this ratio can be even higher if we set an impact range for industrial land, with the buildings within its influence considered as subsidiaries of some industries. Buildings, or buildings attached to the industry, will account for a larger proportion. When the influence range is set to $500 \mathrm{~m}$, the area of the expanded area including industrial land is $52.65 \%$, and when the range is set to $1000 \mathrm{~m}$, the proportion is $53.79 \%$. However, this is only one of the initial impacts we have set. In fact, many large industries will have a greater impact. However, it is undeniable that the expansion of Wuhan City is heavily influenced by industry. More than half of the city's expansion between 2013 and 2016 has been affected by industry.

Table 1. Land use type and percentage in the expansion area.

\begin{tabular}{cc}
\hline Type & Percentage \\
\hline Industrial only & 23.03 \\
\hline Affected by industry (500 m, including industry) & 52.65 \\
\hline Affected by industry (1000 m, including industry) & 53.79 \\
\hline
\end{tabular}




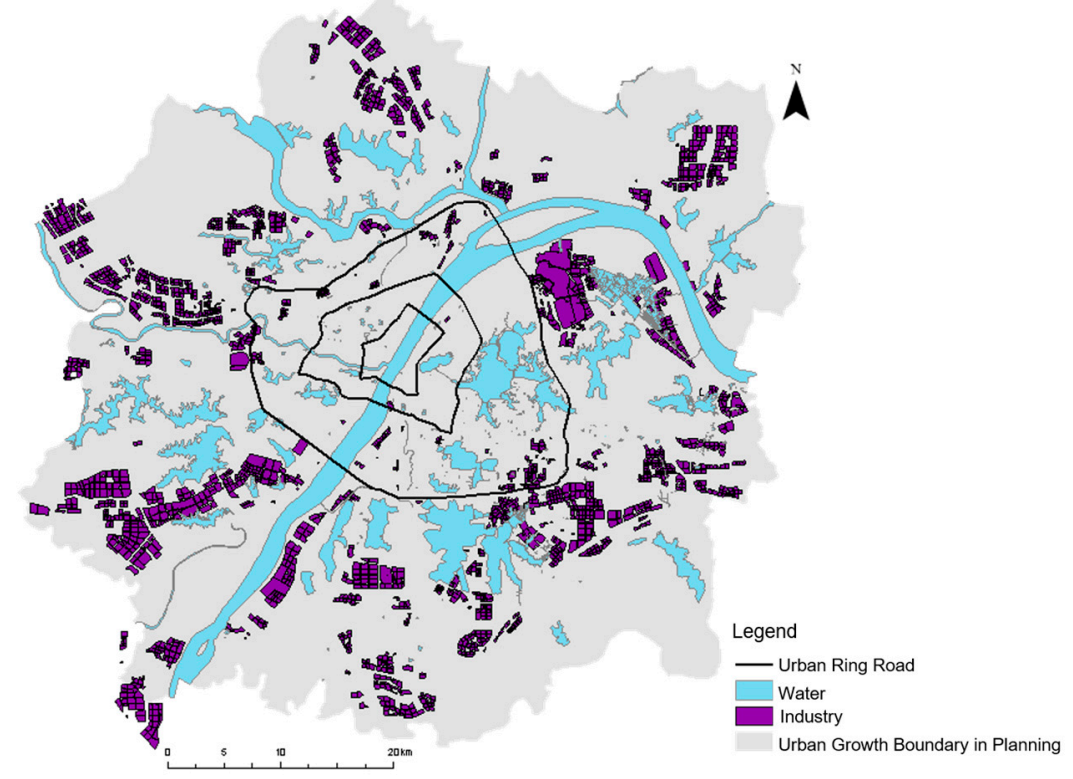

Figure 12. Industrial land use in 2016.

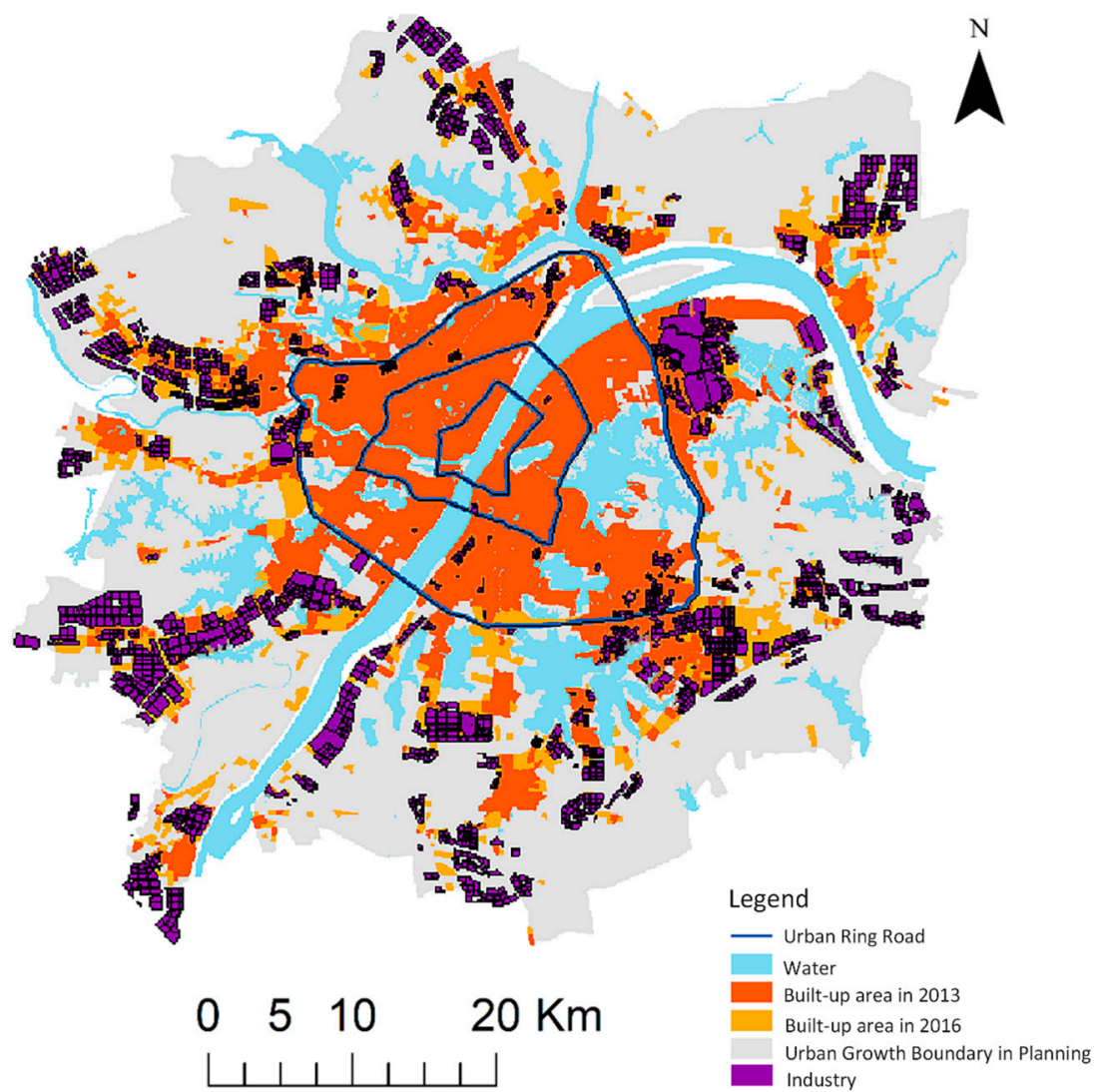

Figure 13. Expansion of the built-up area and the distribution of industrial land use in 2016.

\subsubsection{Change in Accessibility to Urban Public Green Spaces from 2013 to 2016}

By subtracting the accessibility score green spaces of 2013 from that of 2016, the map of changes is shown in Figure 11. Further analysis of the results is made by overlapping the map with the administrative division map (Figure 14) and industry distribution (Figure 15) of Wuhan City. 


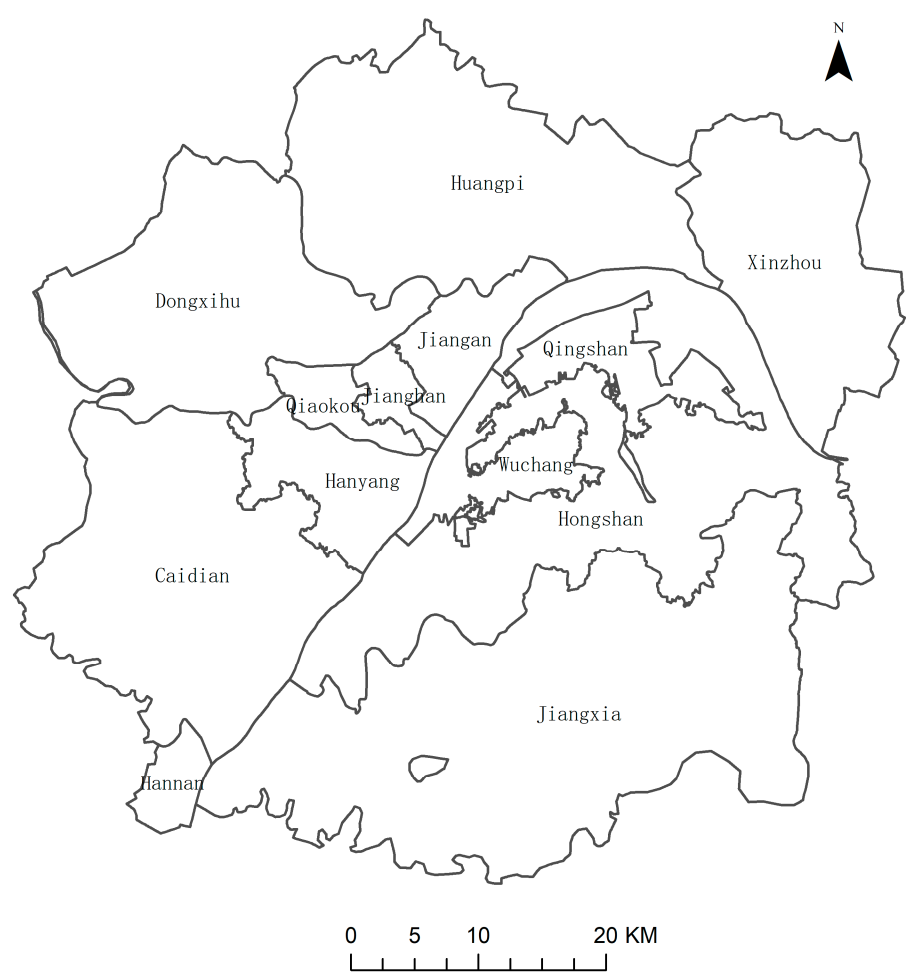

Figure 14. Administrative division of Wuhan.

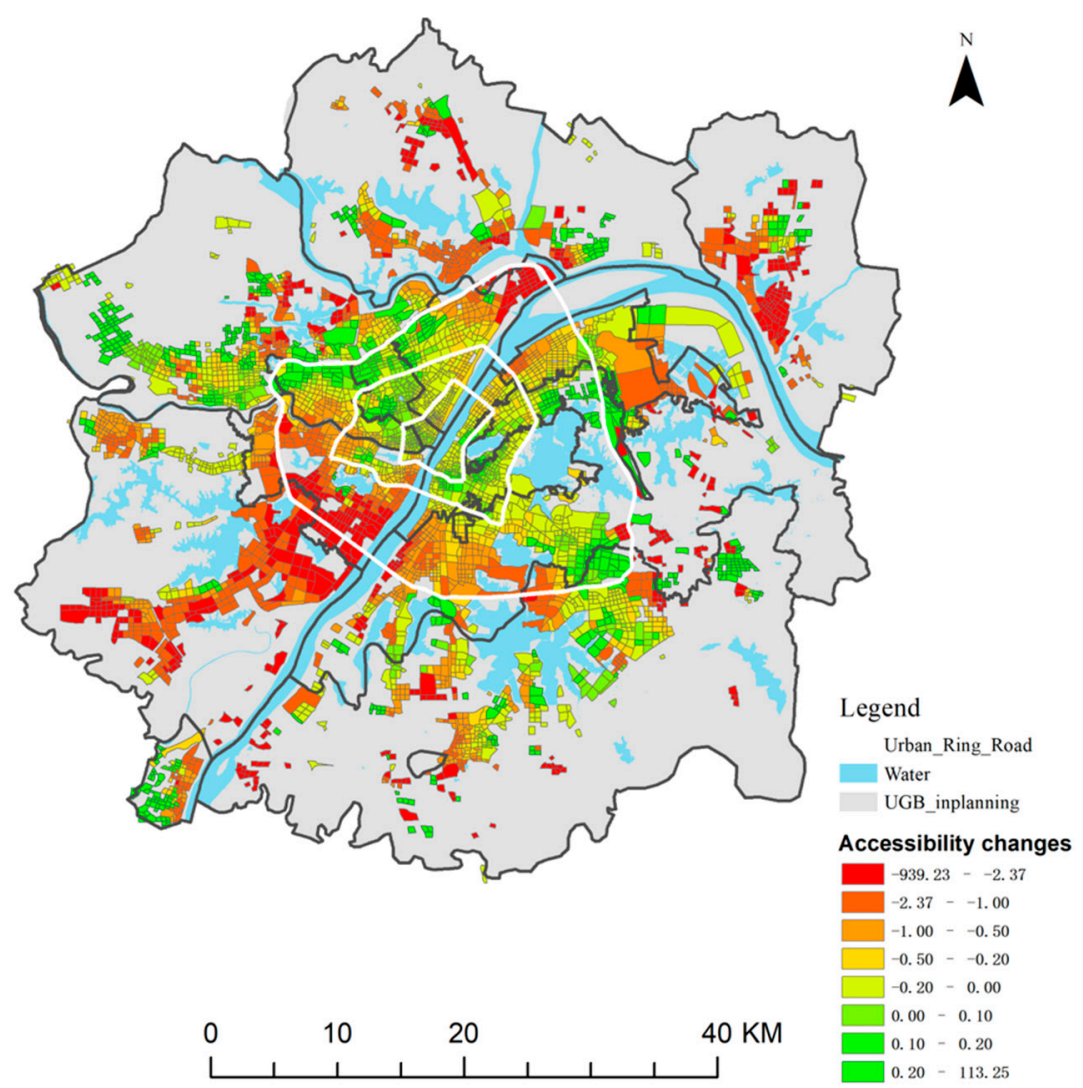

Figure 15. Accessibility differences by administrative division in 2016 over 2013. 
From Figure 15, it can be seen that the green space accessibility in most areas of Jianghan District and nearly half of Qiaokou District has improved within the Third Ring Road within the administrative region. This shows that the government attaches more importance to the planning and development of the region, and the construction of supporting facilities is more comprehensive.

In the Dongxihu District, there are also areas with an obvious increase in park green space accessibility. Different from the Jianghan District and Qiaokou District, which are located in the central urban area within the Third Ring Road, Dongxihu is an area that focuses on industrial development.

When areas with lowered score of accessibility are extracted, as shown in Figure 16, they form a continuous belt within the Caidian District, corresponding well with the industrial development and urban expansion areas in the region. This indicates that when planning and developing the area, the government did not promote the further development of the park green spaces in the area or only added a small amount. At the same time, some other districts with concentrated industrial development-Jiangxia District, Huangpi District, Qingshan District, and Xinzhou District—also saw a similar situation. In these districts, the ratio of areas with declined accessibility scores (including 0 ) is high. However, since these districts had relatively high base scores in green space accessibility, the decline in scores indicates that growing urban population in these districts puts more pressure on park green services. Therefore, the governments should attach more importance to the problem and plan accordingly.

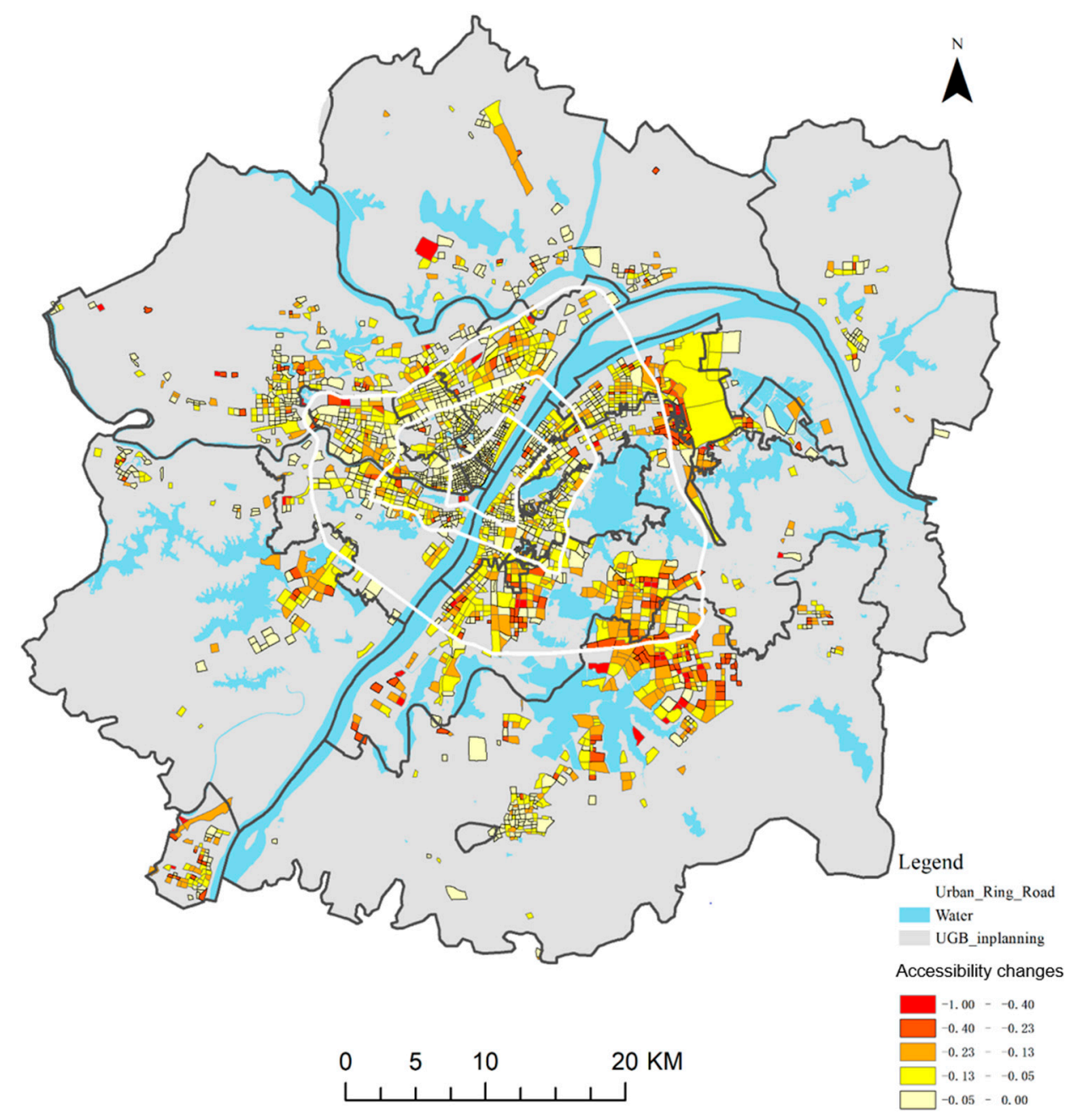

Figure 16. Areas with declined accessibility in 2016 over 2013. 
However, the accessibility score of the Dongxihu District, which also has concentrated industrial development, saw increases in many areas, but still significantly lower than other districts with concentrated industrial development. Furthermore, it is positive that the number of park green spaces and population in the region are both growing. This reason may lie in the fact that development of this district has not met the expectations of the government.

The areas of Jiang'an District and Wuchang District located within the Third Ring Road are nonindustrial areas. Because these are well-established built-up areas with increasing population and low scores of accessibility, it is more difficult to increase the park green spaces in these districts. In addition, the scores of accessibility to green spaces are still declining in these two districts, with Jiang'an District being particularly serious, and its scores in areas along the Yangtze River declining severely.

As for Hannan District, it is located on the urban fringe with a small area located within the study area, and the majority of the district located in the suburbs of Wuhan outside the study area, so the data in the study do not fully reflect its condition. Therefore, it is not analyzed in the present study.

Overall, it is found that industrial development takes precedence over green space. With its vigorous development, industrial land attracts increasing population, resulting in the drastic decline of the service capacity of green spaces.

\section{Discussion}

\subsection{Inequity in Green Space Development}

It can be seen from the results that not many districts in the Wuhan metropolitan area see increased accessibility scores of park green spaces. Combined with population data, it seems that districts with a higher accessibility score of park green space are generally less populated, while those with lower scores are more densely populated. Especially for areas within the central urban area, except for Jianghan District and Qiaokou District, the accessibility scores of park green space are all decreasing. The urban expansion area outside the Third Ring Road can basically be attributed to industrial development in Wuhan, which is accompanied by declined accessibility scores of park green space in respective districts.

Among various districts, Jianghan District, Qiaokou District, and Dongxihu District have attracted more government attention, as exemplified by urban renewal (ecological restoration) in Jianghan District and Qiaokou District, and strengthened ecological preservation efforts in parts of the Dongxihu District. The effect of these measures can be seen in the evident increase in accessibility scores of urban public green spaces in these districts.

As a district with relatively concentrated industrial development, the Dongxihu District has gained attention as can be seen in the strengthened ecological preservation efforts by the government. Through these efforts, the government intends to promote the development of the district, attract more people so as to ease the population pressure on other districts. However, the result did not meet the government's expectations. From the previous analysis, it is known that the ratio of population growth in Dongxihu District is not significant; even when compared with all other districts with concentrated industrial development, the ratio of population growth in Dongxihu District ranks only at the lower-middle level, indicating that although the government has tried to attract more people to the district in the past few years, the public did not seem to respond well to the government's endeavors, or they do not have a positive prospect on the development of the district. This surely deserved the attention of related departments.

At the same time, the practices of Wuhan City, which focuses on ecological development of certain areas, may result in inequality of urban public green spaces in Wuhan. This reflects the imbalanced development of Wuhan, which may negatively affect the decentralization of population in the urban area. This also calls for the attention of the relevant departments of the Wuhan Municipal Government. 


\subsection{Industrial Development and Expansion}

Wuhan is the birthplace of China's modern industry and has always been an important industrial town in modern times. Since the founding of People's Republic of China in 1949 to the mid-1980s, Wuhan ranked at the top in the country in terms of industrial output. After the reform and opening-up, with shifting focus in national development strategy and industrial development reform, Wuhan gradually lost its status as a national central city.

With the proposal of the strategy of the Rise of Central China, Wuhan seized the opportunity to recapture its industrial glory. In the "Twelfth Five-Year Plan," Wuhan proposed the "Doubling of Industrial Development" program, which sets the objective of doubling the values of the city's major economic indicators and the scale of its pillar industries in the next five years. The pressures arising from these doubling objectives, as can be seen from the industrial distribution map of Wuhan, need governing by the administrative districts around the center area of Wuhan.

In 2011, Wuhan City officially launched the "Doubling of Industrial Development" program which achieved remarkable results in just one year of implementation, and the total industrial output value above the designated size reached 739 billion yuan, an increase of $21 \%$. In 2013, the "Doubling of Industrial Development" program accelerated in an comprehensive way, forming four major industrial zones: Great Optics Valley District, China Auto-City, Linkong Economic Zone, and Lingang Industrial Zone.

These industrial-driven developments are not only reflected in the economy, but also urban expansion. The development of modern metropolitan areas shows a pattern of peripheral diffusion that is caused by various factors, including population density, environmental capacity, and employment saturation in the central area of the city. In healthy urbanization, the city's outward expansion should be orderly, and the development of the city should prioritize smart growth [39,40].

The urban expansion/sprawl driven by the "Doubling of Industrial Development" program is an industry-led expansion/sprawl that occurs mainly in the suburban areas. In this race for industrial development, the several suburban districts try to gain the support of the main urban area of Wuhan. Therefore, they placed their industrial zones between their own urban area and the central urban area of Wuhan so as to maximize the connection with the central city. Correspondingly, other types of land use are placed at the side away from Wuhan. This phenomenon can be clearly observed in the map of urban expansion and analysis results in previous sections, which shows that the urban expansion of Wuhan City is basically affected and consistent with the industrial distribution of Wuhan. From Figure 13, it can be seen that expansion areas around industrial development are large, except for those close to more mature and old industrial areas (the chemical industry area, Qingshan District and Hanyang industrial area) and the Hannan district, which is excluded from the analysis. This land replacement model is produced under the pressure of the "Doubling of Industrial Development" program, which is contradictory to the principle that satellite towns should balance land uses. One of the consequences is that the planned green spaces between the suburban areas and the central urban area (the "six green wedges" proposed in the in 2008 Wuhan City Master Plan) are gradually being eroded, and its manifestation is the declined accessibility scores for large urban public green space in industrial areas. In addition, industrial areas are expanding rapidly, making it hard for the planning and development of urban public green spaces to keep up. This "expansion" model of the main urban area makes the city's "smart growth" strategy meaningless, and will also lead to the negligence of the ecological value of park green spaces by planning and construction practitioners.

More in-depth studies are required to see whether this will affect the future development of Wuhan City or bring new problems to the urban development of Wuhan.

\subsection{Contributions and Limitations}

There are three contributions of this study. First, the building of a comprehensive framework, combined with the multilevel radius 2SFCA method is used to measure the temporal-spatial differences in the supply and demand of park services. The 2SFCA methods and improved approaches are 
often used to measure the accessibility of public facilities in terms of the ratio of supply and demand. Therefore, differences between different regions can be compared to measure change in accessibility and equity. Secondly, remote sensing images are used to identify the urban expansion area and related urban data, which helps to analyze the city and understand its development, and to explore the impact of rapid urban expansion on the people, the provision of public services in the city, and to discuss the reasons behind urban expansion. Finally, using the results of the analysis, impacts of Wuhan's planning and development on its ecology and green spaces are discussed.

Although improved methods for calculations are introduced, the present study still has some limitations. First is the lack of more detailed road network data. If more precise road network data were available, accessibility could then be measured by road network distance instead of Euclidean distance; even entrances of residential areas and urban public green spaces can be used as the origin and destination of the road network distance analysis, which could make the accessibility scores more accurate and realistic. At the same time, the impact of ways of travel on service radius could be studied to fully understand accessibility; after all, the residents' behavior may have a significant impact on accessibility. In addition, as analysis on microscale happens, evaluation of changes in availability and equity could be improved across various types of demands, which may be key directions for future studies.

\section{Conclusions}

In this study, accessibility of urban public green spaces in Wuhan City and its changes over two different years are evaluated using the multilevel radius 2SFCA method; through the study, the distribution and accessibility of urban public green spaces in Wuhan City in the year 2013 and 2016 are presented, and it is found that Wuhan tends to focus on the ecological development of certain areas, which causes inequity of urban public green spaces between different districts in Wuhan, and also reflects the imbalanced development of Wuhan. Secondly, by looking at the urban expansion of Wuhan, it is found that the city's expansion/sprawl is mainly driven by industrial development. This kind of industrial-led expansion/sprawl may lead to the negligence of the ecological value of park green spaces by planning and construction practitioners. Both problems require the attention and intervention of relevant government departments.

Author Contributions: Conceptualization, H.J.; investigation, H.J.; methodology, H.J.; visualization, C.L.; writing-original draft, Y.Y.; writing — review and editing, Y.Y. and Z.P. All authors have read and agreed to the published version of the manuscript.

Funding: This research was funded by the National Key Research and Development Program (grant number 2018YFD1100801) and the Opening Foundation of Hunan Engineering and Research Center of Natural Resource Investigation and Monitoring: 2020-7.

Acknowledgments: The authors greatly appreciate the visualization and comments of Fei Shao from Wuhan University, who helped improve this manuscript.

Conflicts of Interest: The authors declare no conflict of interest.

\section{References}

1. Bai, X.; Chen, J.; Shi, P. Landscape urbanization and economic growth in China: Positive feedbacks and sustainability dilemmas. Environ. Sci. Technol. 2012, 46, 132-139. [CrossRef]

2. Wei, Y.D.; Ye, X. Urbanization, urban land expansion and environmental change in China. Stoch. Environ. Res. Risk Assess. 2014, 28, 757-765. [CrossRef]

3. Ewing, R.; Hamidi, S.; Grace, J.B.; Wei, Y.D. Does urban sprawl hold down upward mobility? Landsc. Urban Plan. 2016, 148, 80-88. [CrossRef]

4. Wei, Y.D. Regional Development in China: States, Globalization and Inequality; Routledge: Abingdon, UK, 2013.

5. Wu, J.; Xiang, W.N.; Zhao, J. Urban ecology in China: Historical developments and future directions. Landsc. Urban Plan. 2014, 125, 222-233. [CrossRef] 
6. Kabisch, N.; Qureshi, S.; Haase, D. Human-environment interactions in urban green spaces-A systematic review of contemporary issues and prospects for future research. Environ. Impact Assess. Rev. 2015, 50, $25-34$. [CrossRef]

7. Chen, W.Y.; Jim, C.Y. Resident motivations and willingness-to-pay for urban biodiversity conservation in Guangzhou (China). Environ. Manag. 2010, 45, 1052-1064. [CrossRef]

8. Wolch, J.R.; Byrne, J.; Newell, J.P. Urban green space, public health, and environmental justice: The challenge of making cities "just green enough". Landsc. Urban Plan. 2014, 125, 234-244. [CrossRef]

9. Bowler, D.E.; Buyung-Ali, L.; Knight, T.M.; Pullin, A.S. Urban greening to cool towns and cities: A systematic review of the empirical evidence. Landsc. Urban Plan. 2010, 97, 147-155. [CrossRef]

10. World Health Organization. Urban Green Space Interventions and Health: A Review of Impacts and Effetiveness; World Health Organization: Geneva, Switzerland, 2017.

11. Yao, L.; Liu, J.; Wang, R.; Yin, K.; Han, B. Effective green equivalent-A measure of public green spaces for cities. Ecol. Indic. 2014, 47, 123-127. [CrossRef]

12. Xiao, Y.; Wang, Z.; Li, Z.; Tang, Z. An assessment of urban park access in Shanghai-Implications for the social equity in urban China. Landsc. Urban Plan. 2017, 157, 383-393. [CrossRef]

13. Ye, C.; Hu, L.; Li, M. Urban green space accessibility changes in a high-density city: A case study of Macau from 2010 to 2015. J. Transp. Geogr. 2018, 66, 106-115. [CrossRef]

14. Yuan, Y.; Xu, J.; Wang, Z. Spatial equity measure on urban ecological space layout based on accessibility of socially vulnerable groups-A case study of Changting, China. Sustainability 2017, 9, 1552. [CrossRef]

15. Wu, H.; Liu, L.; Yu, Y.; Peng, Z. Evaluation and planning of urban green space distribution based on mobile phone data and two-step floating catchment area method. Sustainability 2018, 10, 214. [CrossRef]

16. Davis, C.; Schaub, T. A transboundary study of urban sprawl in the Pacific Coast region of North America: The benefits of multiple measurement methods. Int. J. Appl. Earth Obs. Geoinf. 2005, 7, 268-283. [CrossRef]

17. Ewing, R. Is Los Angeles-Style Sprawl Desirable? J. Am. Plan. Assoc. 1997, 63, 107-126. [CrossRef]

18. Pendall, R. The limitless city: A primer on the urban sprawl debate. J. Am. Plan. Assoc. 2003, 69, 99.

19. Hamidi, S.; Ewing, R.; Preuss, I.; Dodds, A. Measuring Sprawl and Its Impacts: An Update. J. Plan. Educ. Res. 2015, 35, 35-50. [CrossRef]

20. Brueckner, J.K. Urban sprawl: Diagnosis and remedies. Int. Reg. Sci. Rev. 2000, 23, 160-171. [CrossRef]

21. Gao, B.; Huang, Q.; He, C.; Sun, Z.; Zhang, D. How does sprawl differ across cities in China? A multi-scale investigation using nighttime light and census data. Landsc. Urban Plan. 2016, 148, 89-98. [CrossRef]

22. He, Q.; Song, Y.; Liu, Y.; Yin, C. Diffusion or coalescence? Urban growth pattern and change in 363 Chinese cities from 1995 to 2015. Sustain. Cities Soc. 2017, 35, 729-739. [CrossRef]

23. Klein Goldewijk, K.; Beusen, A.; Janssen, P. Long-term dynamic modeling of global population and built-up area in a spatially explicit way: HYDE 3.1. Holocene 2010, 20, 565-573. [CrossRef]

24. Zhang, J.; Li, P.; Wang, J. Urban built-Up area extraction from landsat TM/ETM+ images using spectral information and multivariate texture. Remote Sens. 2014, 6, 7339-7359. [CrossRef]

25. Guagliardo, M.F. Spatial accessibility of primary care: Concepts, methods and challenges. Int. J. Health Geogr. 2004, 3. [CrossRef] [PubMed]

26. Luo, W.; Qi, Y. An enhanced two-step floating catchment area (E2SFCA) method for measuring spatial accessibility to primary care physicians. Health Place 2009, 15, 1100-1107. [CrossRef]

27. Fan, P.; Xu, L.; Yue, W.; Chen, J. Accessibility of public urban green space in an urban periphery: The case of Shanghai. Landsc. Urban Plan. 2017, 165, 177-192. [CrossRef]

28. Xing, L.; Liu, Y.; Liu, X.; Wei, X.; Mao, Y. Spatio-temporal disparity between demand and supply of park green space service in urban area of Wuhan from 2000 to 2014. Habitat Int. 2018, 71, 49-59. [CrossRef]

29. Widener, M.J.; Farber, S.; Neutens, T.; Horner, M.W. Using urban commuting data to calculate a spatiotemporal accessibility measure for food environment studies. Health Place 2013, 21, 1-9. [CrossRef]

30. Neutens, T.; Schwanen, T.; Witlox, F. The prism of everyday life: Towards a new research agenda for time geography. Transp. Rev. 2011, 31, 25-47. [CrossRef]

31. Luo, W.; Wang, F. Measures of spatial accessibility to health care in a GIS environment: Synthesis and a case study in the Chicago region. Environ. Plan. B Plan. Des. 2003, 30, 865-884. [CrossRef]

32. Dai, D. Black residential segregation, disparities in spatial access to health care facilities, and late-stage breast cancer diagnosis in metropolitan Detroit. Health Place 2010, 16, 1038-1052. [CrossRef] 
33. Jamtsho, S.; Corner, R.; Dewan, A. Spatio-temporal analysis of spatial accessibility to primary health care in Bhutan. ISPRS Int. J. Geo-Inf. 2015, 4, 1584-1604. [CrossRef]

34. Lin, B.C.; Chen, C.W.; Chen, C.C.; Kuo, C.L.; Fan, I.C.; Ho, C.K.; Liu, I.C.; Chan, T.C. Spatial decision on allocating automated external defibrillators (AED) in communities by multi-criterion two-step floating catchment area (MC2SFCA). Int. J. Health Geogr. 2016, 15, 17. [CrossRef] [PubMed]

35. Wang, F. Measurement, Optimization, and Impact of Health Care Accessibility: A Methodological Review. Ann. Assoc. Am. Geogr. 2012, 102, 1104-1112. [CrossRef] [PubMed]

36. Wang, F. Quantitative Methods and Applications in GIS; CRC Press: Boca Raton, FL, USA, 2006.

37. Cheng, Y.; Wang, J.; Rosenberg, M.W. Spatial access to residential care resources in Beijing, China. Int. J. Health Geogr. 2012, 11, 32. [CrossRef] [PubMed]

38. Rasouli, S.; Timmermans, H. Assessment of model uncertainty in destinations and travel forecasts of models of complex spatial shopping behaviour. J. Retail. Consum. Serv. 2013, 20, 139-146. [CrossRef]

39. Geller, A.L. Smart Growth: A Prescription for Livable Cities. Am. J. Public Health 2003, 93, 1410-1415. [CrossRef] [PubMed]

40. Jepson, E.J.; Edwards, M.M. How possible is sustainable urban development? an analysis of planners' perceptions about new urbanism, smart growth and the ecological city. Plan. Pract. Res. 2010, 25, 417-437. [CrossRef]

Publisher's Note: MDPI stays neutral with regard to jurisdictional claims in published maps and institutional affiliations. 